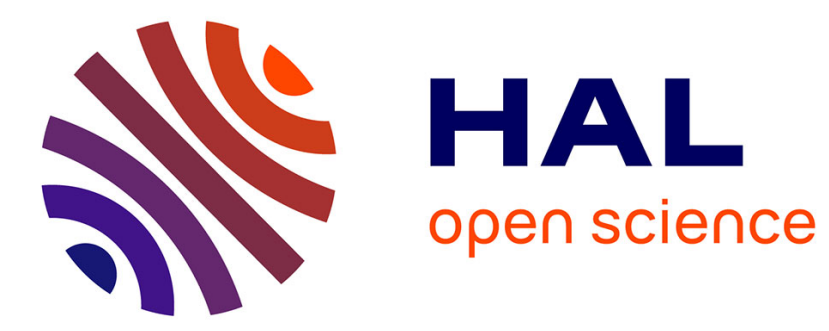

\title{
A DC corona discharge on a flat plate to induce air movement
}

Pierre Magnier, Dunpin Hong, Annie Leroy-Chesneau, Jean-Michel Pouvesle, Jacques Hureau

\section{- To cite this version:}

Pierre Magnier, Dunpin Hong, Annie Leroy-Chesneau, Jean-Michel Pouvesle, Jacques Hureau. A DC corona discharge on a flat plate to induce air movement. Journal of Electrostatics, 2007, 65 (10-11), pp. 655-659. 10.1016/j.elstat.2007.04.002 . hal-00264829

\section{HAL Id: hal-00264829 \\ https://hal.science/hal-00264829}

Submitted on 18 Mar 2008

HAL is a multi-disciplinary open access archive for the deposit and dissemination of scientific research documents, whether they are published or not. The documents may come from teaching and research institutions in France or abroad, or from public or private research centers.
L'archive ouverte pluridisciplinaire HAL, est destinée au dépôt et à la diffusion de documents scientifiques de niveau recherche, publiés ou non, émanant des établissements d'enseignement et de recherche français ou étrangers, des laboratoires publics ou privés. 


\title{
A DC corona discharge on a flat plate to induce air movement
}

\author{
Pierre MAGNIER ${ }^{1}$, Dunpin HONG ${ }^{2}$, Annie LEROY-CHESNEAU ${ }^{1}$, Jean- \\ Michel POUVESLE ${ }^{2}$, Jacques HUREAU ${ }^{1}$ \\ ${ }^{1}$ Laboratoire de Mécanique et d'Energétique \\ 8, rue Leonard de Vinci 45072 Orléans Cedex 2 France \\ ${ }^{2}$ GREMI, UMR 6606 CNRS/Université d'Orléans \\ 14, rue d'Issoudun 45072 Orléans Cedex 2 France
}

\begin{abstract}
This paper describes a DC surface corona discharge designed to modify the airflow around a flat plate. The electrode configuration consisted of two thin copper layers placed on each side of the plate's attack edge. Discharge optical measurements with a photomultiplier tube indicated that the light emitted by the plasma is pulsating, at a frequency that increases with applied voltage. Moreover, with voltage higher than a threshold value, the electric discharge changes regime with brighter pulses. This discharge also induced an "ionic wind" whose velocity was measured with a pressure sensing probe (up to $1 \mathrm{~m} / \mathrm{s}$ ). Experiments with the Particle Image Velocimetry system in a subsonic wind tunnel showed that this discharge can reduce the separated airflow on the flat plate for a flow of $14 \mathrm{~m} / \mathrm{s}$ (Reynolds number of 187,000).
\end{abstract}

Keywords: Corona Discharge; Electroaerodynamics; Ionic Wind; Plasma Actuator. 


\section{Introduction}

The use of so-called ionic wind induced by a high voltage discharge [1] has been studied in electrostatic precipitators [2-3] and, more recently, in aerodynamics [4]. In this latter case, the ionic wind is used to modify the airflow around an obstacle in order to control the airflow in the boundary layer and reduce drag. For this purpose, different electric discharges have recently been developed, such as the "One Atmosphere Uniform Glow Discharge Plasma" [5-6] and DC surface corona discharges [7-9]. Labergue et al. [7] used the latter discharge on an inclined wall to detach the flow; Léger et al. [8] and Artana et al. [9] re-attached the flow on a flat plate. Published results indicate that the discharge can be used for active control of low velocity airflow, but the mechanism of interaction between discharge and flow has not yet been clarified.

In this paper, we present an investigation of a DC corona discharge and measurements of the induced flow. The electrode configuration consisted of two metallic tapes placed on each side of a circular leading edge (see Fig. 1). This configuration slightly differs from that in reported works [8-9], where both wire electrodes were placed on the same side of the attack edge.

\section{Experimental setup}

\subsection{Plasma actuator and power supply}

The plasma actuator consisted of a DC surface-corona discharge established between two electrodes (copper, $170 \mathrm{~mm}$ long, $25 \mathrm{~mm}$ wide and 35 
$\mu \mathrm{m}$ thickness) mounted on both sides of the circular leading edge of a flat plate (PVC, polyvinyl chloride, $213 \times 200 \times 15 \mathrm{~mm}$ ), as shown in Fig. 1. The anode was placed $7.5 \mathrm{~mm}$ downstream of the leading edge and connected to a positive high voltage source (SPELLMAN SL300, 0-60 kV, $5 \mathrm{~mA}$ ); the cathode, placed $37 \mathrm{~mm}$ from the edge, was connected to ground. A $15-\mathrm{M} \Omega$ series resistor prevented the transition to an arc regime.

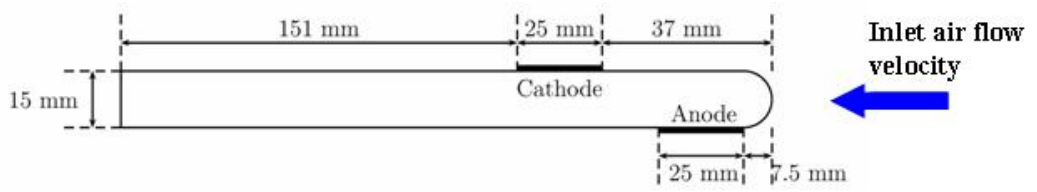

Figure 1: DC surface corona discharge actuator on a flat plate.

\subsection{Optical Setup}

As the light emitted by the discharge was very weak, a highly sensitive photomultiplier tube (Hamamatsu R928 having a spectral domain from $185 \mathrm{~nm}$ to $900 \mathrm{~nm}$ ) was used to detect the plasma fluorescence. A load resistance of 10 $\mathrm{k} \Omega$ was placed between the anode of the PMT and ground to measure the photocurrent. The rise time of the detection system was about 200 ns. The PMT signal was measured with an oscilloscope. The setup shown in Fig. 2 used a quartz lens to capture the ultraviolet (UV) light from the discharge.

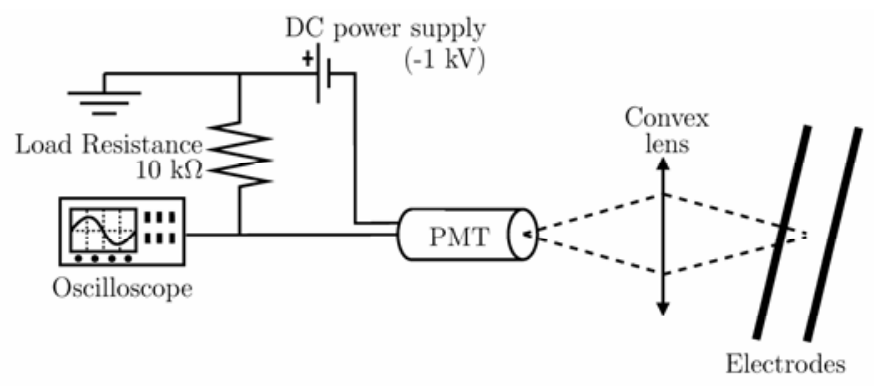

Figure 2: Optical setup for measurements using photomultiplier tube 


\subsection{Wind tunnel}

Experiments with external airflow were performed in a subsonic wind tunnel (Fig. 3) of $50 \mathrm{~cm} \times 50 \mathrm{~cm}$ cross-section in a 2-m long test section (mean turbulence ratio of $0.5 \%$ ), where a flow with maximum velocity of $50 \mathrm{~m} / \mathrm{s}$ was generated by a $30-\mathrm{kW}$ electric fan. The test flat plate was placed between two transparent rotating disks, shown in the test section in Fig. 3, which allow for obtaining the desired attack angle.

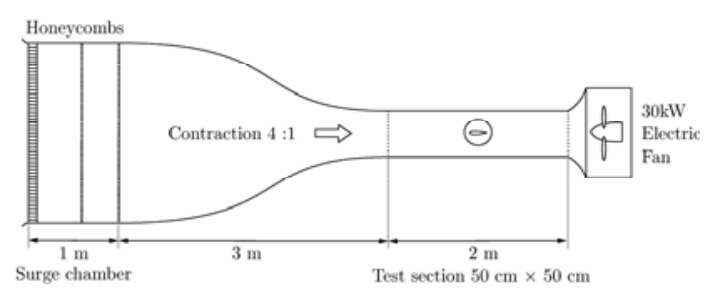

Figure 3: Schematic side view of the wind tunnel

\subsection{Particle Image Velocimetry system}

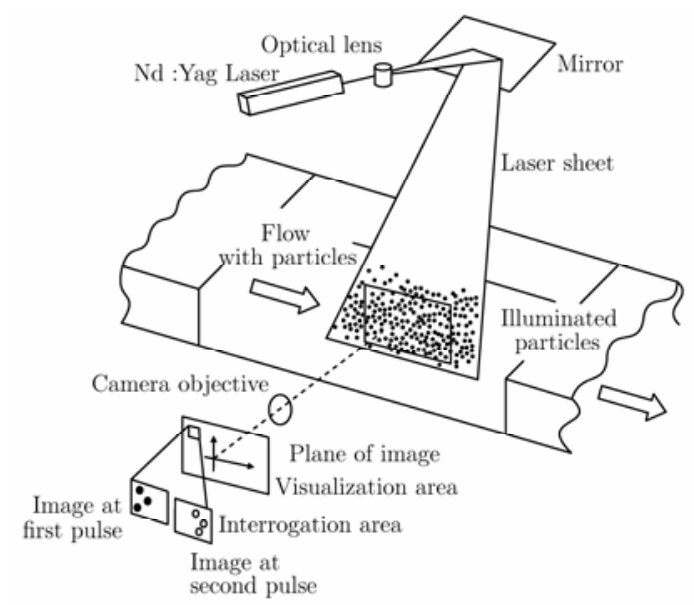

Figure 4: Experimental setup of the Particle Image Velocimetry system.

Measurements of the flow velocity fields were performed using the Particle Image Velocimetry (PIV) system shown in Fig. 4. A laser beam of wavelength $532 \mathrm{~nm}(\mathrm{Nd}$ :Yag laser, Spectra Physics 400) was transformed into a laser light sheet using mirrors and lenses. The laser sheet illuminated smoke 
particles (generated by incense sticks) which seeded the flow. Images of illuminated smoke particles were captured using a Charge Coupled Device (CCD) camera called PIVCAM. The vector displacement of each particle could be determined using two images recorded for two successive laser pulses having a time delay of $10 \mu \mathrm{s}$. The velocity fields presented in this paper are the mean vector fields of 500 pairs of such images recorded over a duration of 50 seconds at repetition rate of $10 \mathrm{~Hz}$.

\subsection{Pressure sensing probe}

Velocity measurements were made with a pressure sensing probe consisting of a tube made of glass, shown in Fig. 5, thus avoiding conductive materials near the discharge that could cause unwanted arcs. The tube was connected to a differential low-pressure transducer Druck $^{\mathrm{TM}}$ LPM 9481 (0-20 $\mathrm{Pa}$, output voltage 0-5 V) and measurements were acquired on a PC using a 16bit acquisition card, over a $2-\mathrm{s}$ interval at a $2-\mathrm{kHz}$ sampling rate. The flow velocity $V$ was determined from the differential pressure values $\Delta P$ using the Bernoulli relation $\Delta P=1 / 2 \rho V^{2}$, where $\rho$ is the air density. This sensor was calibrated with a classical Pitot tube in a calibration wind tunnel (DANTEC StreamLine 90H02 Flow Unit).

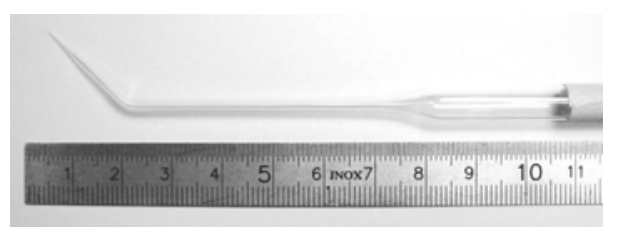

Figure 5: Pressure sensing probe made of glass.

\section{Results and discussion}




\subsection{Discharge characteristics}

Using the configuration presented in Fig. 1, a stable discharge was obtained using a positive DC high voltage of $44 \mathrm{kV}$ as shown by the photography in Fig. 6 . The room's relative humidity was $44 \%$. This photo was taken using an intensified CCD camera with a gating time of 1 second. The mean discharge current was $0.20 \mathrm{~mA}$. The current per unit length of the electrode perpendicular to the edge was thus $1.2 \mathrm{~mA} / \mathrm{m}$. This value is approximately the same as that used by others authors [7-10].

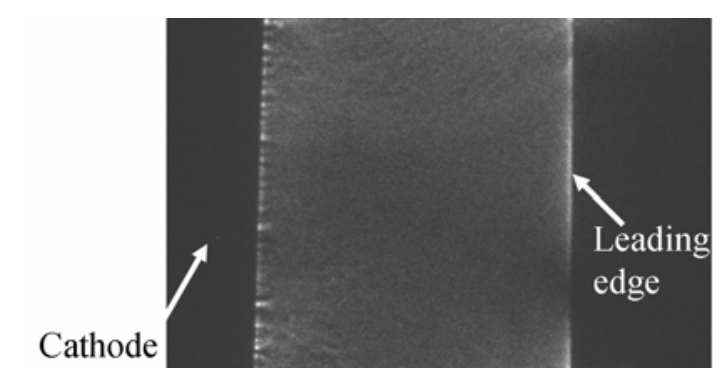

Figure 6: Photography of the discharge established on the flat plate.

This apparent homogeneity in fact hides a much more complex time structure. Indeed, time resolved measurements using the PMT, shown in Fig. 7.a, reveal that the discharge is composed of a multitude of streamers at a repetition rate that depends on the working voltage. Notice that each negative peak of the PMT signal corresponds to a light pulse emitted by a streamer (called a "micro-discharge" in this paper in consideration of the low value of the corresponding measured intensity) mainly in UV range (because the light was strongly 

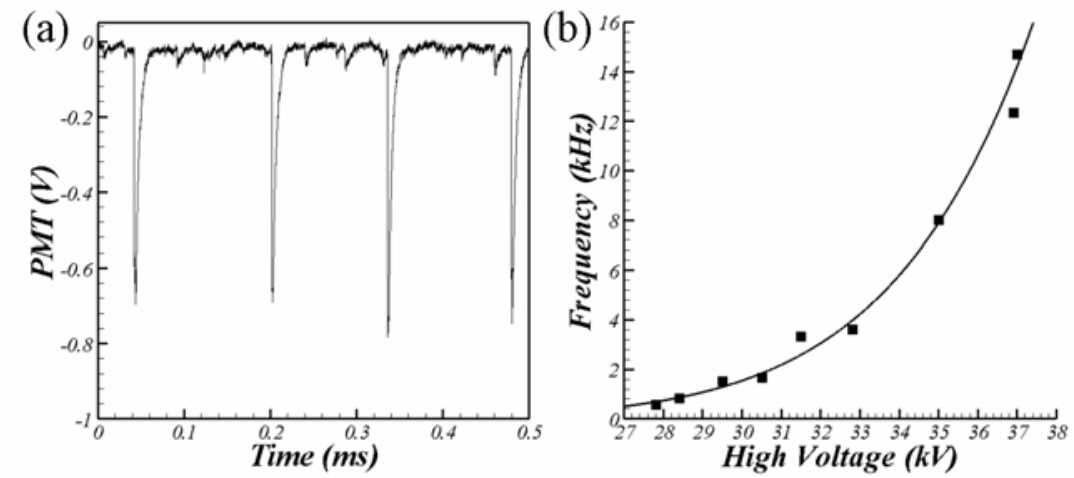

Figure 7: (a) Time evolution of corona discharges at $35 \mathrm{kV}$, and (b) frequency of the corona micro-discharges versus high voltage.

attenuated by glass non-transparent to UV). The frequency as a function of working voltage, up to $38 \mathrm{kV}$, is shown in Fig7.b. Despite the constancy of voltage, the corona discharge can be an intermittent one as shown by PMT measurement. This intermittence was discovered in Loeb's laboratory in 1938 [11]. In case of a negative corona, the pulses are called Trichel pulses and its frequency is much higher than the one of positive corona used in this experiment [12]

In our specific setup, the discharge regime changed when the working voltage was higher than $38.5 \mathrm{kV}$. Indeed, the appearance of the discharge became much more luminous and visible to the naked eye. The PMT signal, in Fig. 8, showed the appearance of some stronger discharges (called macrodischarges in this paper). Each macro-discharge caused a voltage drop as shown by the second curve in Fig. 8 . 


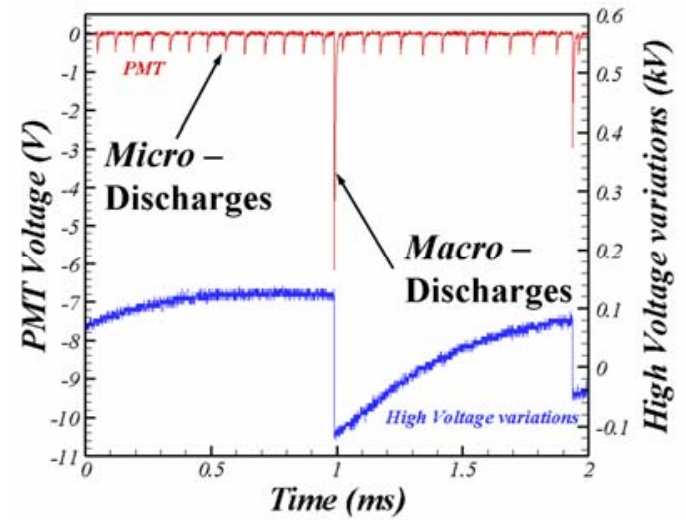

Figure 8: Time evolution of corona discharges and high voltage variations at $39 \mathrm{kV}$.

\subsection{Induced flow velocity}

In an initially still atmosphere, the DC surface corona discharge induces airflow (called ionic wind) due to the movement of positive ions from anode to cathode. Usually, plasma is composed mainly of electron and positive ions. However, due to the electron attachment, plasma created in air also contains negative ions of oxygen. But the effect of these negative ions is less important than the effect of positive ions because the induced airflow is always from anode to cathode in the case of a positive working voltage [10]. This weak contribution of negative ions is probably due to a lower concentration of these ions.

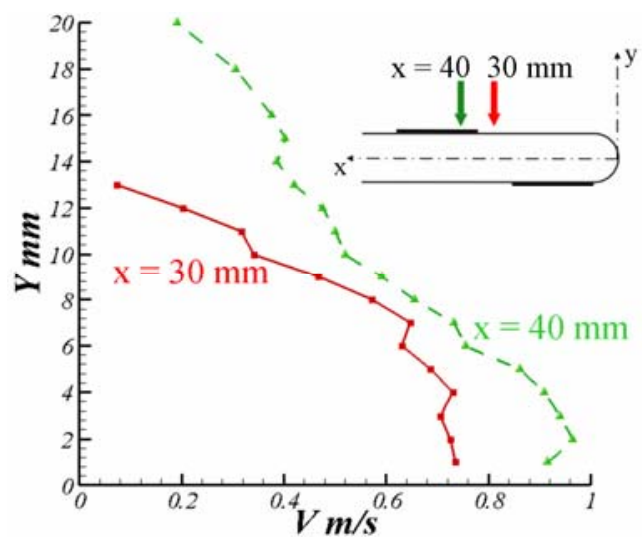


Figure 9: Ionic wind velocity profiles at different positions (44 kV).

The induced flow velocity profiles at two positions were measured and results are given in Fig. 9 for a working voltage of $44 \mathrm{kV}$. The maximum of the time-averaged velocity values, obtained above the cathode, was about $1 \mathrm{~m} / \mathrm{s}$.

\subsection{Airflow modification by plasma}
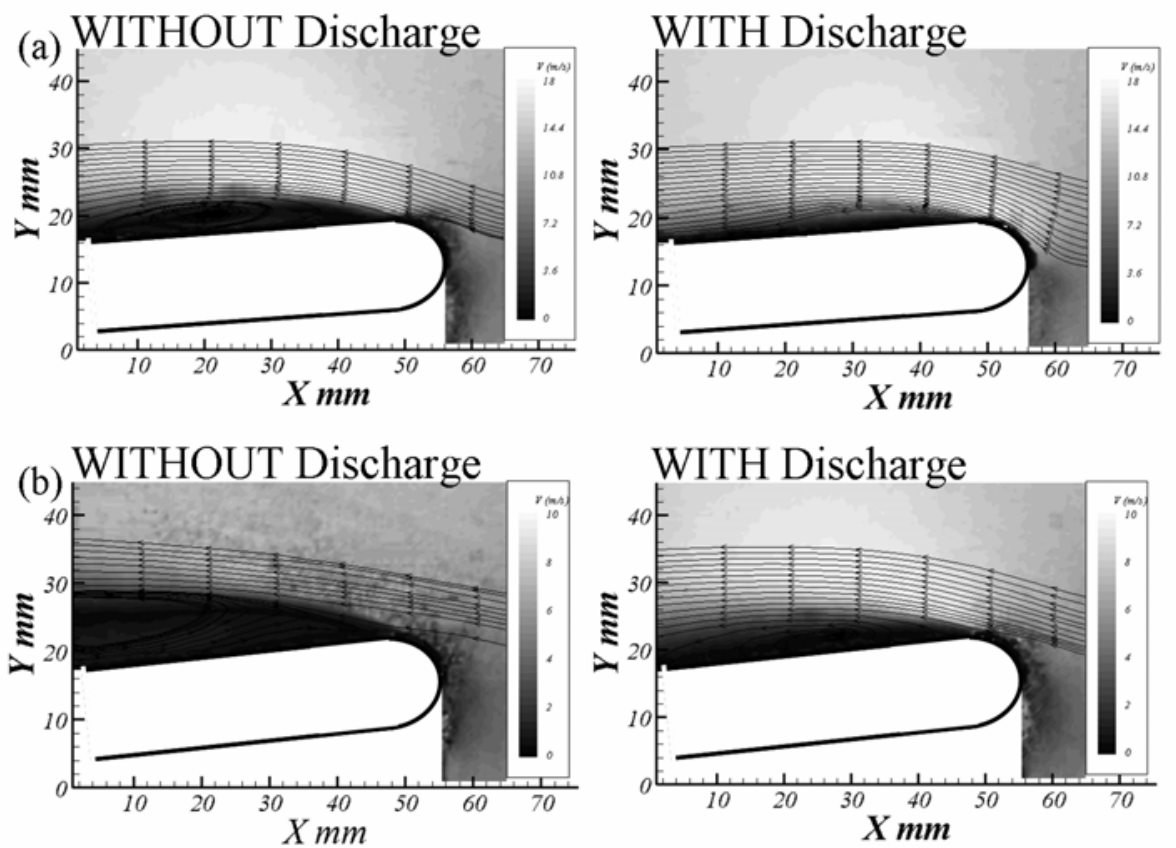

Figure 10: Time averaged velocity fields with and without discharge $(40 \mathrm{kV}$, $0.8 \mathrm{~mA} / \mathrm{m}$ ) (a) for an angle of attack of $2.5^{\circ}$, and an inlet flow velocity of 14 $\mathrm{m} / \mathrm{s}$, (b) for $5^{\circ}$ and $8 \mathrm{~m} / \mathrm{s}$.

The flat plate equipped with the DC plasma actuator was installed in the wind tunnel (see Fig. 3). Velocity field measurements were performed using the PIV system, with and without plasma. Results with streamlines deduced from velocity fields are shown in Fig. 10. The separation bubble size decreased with the electric discharge (angle of attack of $2.5^{\circ}$, inlet airflow velocity in the wind tunnel of $14 \mathrm{~m} / \mathrm{s}$, a Reynolds number of 187,000, Fig. 10.a), and the fully separated flow was re-attached beyond a bubble $\left(5^{\circ}, 8 \mathrm{~m} / \mathrm{s}, \mathrm{Re}=107,000\right.$, Fig. 
10.b). This clearly visible effect was obtained at rather high Reynolds numbers compared to those previously reported [6] (up to 68,600 in this mentioned work) also with a DC corona discharge on a flat plate.

\section{Conclusion}

A DC surface corona discharge established between two thin copper layer electrodes placed on each side of the plate attack edge is presented in this paper. Although the plasma appears as a homogeneous layer, measurements with a photomultiplier tube showed that it is, in fact, composed of a multitude of small, pulsed discharges, whose repetition frequency increases with applied high voltage.

The positive ion movement in the plasma induced airflow around the flat plate. Measurements with a pressure sensing probe indicate that the maximum mean velocity of ionic wind in the configuration studied was about 1 $\mathrm{m} / \mathrm{s}$. This value is quite low compared to the airflow in the wind tunnel, but even in these conditions, the presence of the plasma was efficient in reducing the separated flow on the flat plate in a subsonic wind tunnel, for a flow velocity of $14 \mathrm{~m} / \mathrm{s}$ (Reynolds number of 187,000). This result encourages further studies on a wing airfoil in a subsonic wind tunnel.

\section{Acknowledgements}

The authors would like to thank Stéphane Loyer (LME), Erwan Le Menn and Guy Coudrat (GREMI) for their assistance during these experiments. We would also like to thank Dr. Luc Leger for helpful discussions. 


\section{References}

[1] M. Robinson, Movement of air in the electric wind of the corona discharge. AIEE transactions, vol. 80 (1961), pp. 143-150.

[2] G.L. Leonard, M. Mitchner, S.A. Self, An experimental study of the electrohydrodynamic flow in electrostatic precipitators. J. Fluid Mech., vol. 127 (1983), pp. 123--140.

[3] A. Soldati, S. Banerjee, Turbulence modification by large-scale organized electrohydrodynamic flows. Phys. Fluids, vol. 10, No. 7 (1998), pp. 1742-1756.

[4] S. El-Khabiry, G. Colver, Drag reduction by DC corona discharge along an electrically conductive flat plate for small Reynolds number flows. Phys. Fluids, vol. 9 (3) (1997), pp. 587-599.

[5] J. R. Roth, D. M. Sherman, S. P. Wilkinson, Boundary layer flow control with a One Atmosphere Uniform Glow Discharge surface plasma. AIAA Paper, 98-0328 (1998).

[6] J. R. Roth, H. Sin, R. C. M. Madhan, S. P. Wilkinson, Flow re-attachement and acceleration by paraelectric and peristaltic electrohydrodynamic (EHD) effects. AIAA Paper, 2004--0845 (2004).

[7] A. Labergue, L. Léger, E. Moreau, G. Touchard, Effect of a plasma actuator on an airflow along an inclined wall: P.I.V. and wall pressure measurements. J. Electrostat., vol. 63 (2005), pp. 961-967. 
[8] L. Léger, E. Moreau, G. Artana, G. Touchard, Influence of a DC corona discharge on the airflow along an inclined flat plate. J. Electrostat., vol. 51-52 (2001), pp. 300-306.

[9] G. Artana, J. D'Adamo, L. Léger, E. Moreau, G. Touchard, Flow control with electrohydrodynamic actuators. AIAA Journal, vol. 40, No. 9 (2002), pp. 1773-1779.

[10] E. Moreau, L. Léger, G. Touchard, Effect of a DC surface-corona discharge on a flat plate boundary layer for air flow velocity up to $25 \mathrm{~m} / \mathrm{s}$. J. Electrostat., vol. 64, issues 3-4 (2005), pp. 215-225.

[11] G.W. Trichel, The mechanism of the negative point to plane corona near onset, Phys. Rev. 54 (1938), pp. 1078-1084.

[12] Y.P. Raiser, Gas Discharges Physics, corrected 2nd printing 1997, Springer, P351. 